\title{
Surveys of postpartum depression in Miyagi, Japan, after the Great East Japan Earthquake
}

\author{
Hidekazu Nishigori • Junichi Sugawara • Taku Obara • \\ Toshie Nishigori • Kineko Sato $\cdot$ Takashi Sugiyama • \\ Kunihiro Okamura $\cdot$ Nobuo Yaegashi
}

Received: 10 April 2014 / Accepted: 1 September 2014 / Published online: 10 September 2014

(C) The Author(s) 2014. This article is published with open access at Springerlink.com

\begin{abstract}
This study explores the correlation between the impact of the Great East Japan Earthquake and the incidence of postpartum depression in Miyagi prefecture, Japan. The design used was a cross-sectional study with self-administered questionnaires, 6-9 months after the disaster. The results showed the prevalence of postnatal women with Edinburgh Postnatal Depression Scale (EPDS) score of $\geq 9$ to be $21.3 \%$. Multivariate analysis showed that exposure to tsunami (odds ratio, 1.80; $95 \%$ confidence interval, 1.16-2.78) was significantly and independently associated with an EPDS score of $\geq 9$. Postnatal women and their children should be treated as a vulnerable population, and a protective framework must be established to prepare for future devastating disasters.
\end{abstract}

Keywords Great East Japan Earthquake · Tsunami ·

Postpartum depression - Edinburgh Postnatal Depression Scale (EPDS)

H. Nishigori $\cdot$ J. Sugawara $\cdot$ T. Sugiyama $\cdot$ N. Yaegashi

Department of Obstetrics and Gynecology, Tohoku University

Graduate School of Medicine, Sendai, Japan

J. Sugawara $\cdot$ T. Obara $\cdot$ T. Nishigori $\cdot$ N. Yaegashi

Tohoku Medical Megabank Organization, Tohoku University,

Sendai, Japan

K. Sato

Department of Health Sciences, Tohoku University Graduate School

of Medicine, Sendai, Japan

K. Okamura

Tohoku Kohsai Hospital, Sendai, Japan

J. Sugawara $(\bowtie)$

Division of Feto-Maternal Medical Science, Tohoku Medical

Megabank Organization, Tohoku University, 2-1 Seiryocho,

Aobaku, Sendai, Miyagi 980-8573, Japan

e-mail: jsugawara@med.tohoku.ac.jp

\section{Introduction}

Miyagi prefecture is located on the eastern coast of Japan. Following the Great East Japan Earthquake and Tsunami on March 11, 2011, approximately 12,000 people died or went missing, and more than 460,000 houses and buildings were completely or partially destroyed. Previous studies have addressed that maternal mental health (such as perinatal depression) can be influenced by the devastation caused by a natural disaster (Harville et al. 2009). Perinatal depression affects postnatal women's health and may impact not only the newborn infant's quality of care but also the subsequent growth and development of the women's children. In the present study, we examined the Edinburgh Postnatal Depression Scale (EPDS) for postpartum depression and its risk factors (Cox et al. 1987) to assess the Great East Japan Earthquake's influence on perinatal women's mental health in Miyagi prefecture.

\section{Materials and method}

Study subjects

The study design was cross sectional. Participants were recruited from 15 hospitals and 11 clinics in the coastal area of Miyagi prefecture. They delivered between February 1, 2011, and October 31, 2011, and their homes were destroyed by the tsunami. From September 1 to November 30, 2011, the study's explanatory leaflet and the agreement document were delivered by mail to 3539 postpartum women. The selfadministered questionnaires went to 683 participants, who had agreed with the study, and 677 questionnaires were returned. The Ethics Committee of the Tohoku University Graduate School of Medicine approved this study on June 27, 2011 (Number 2011-103). 
Fig. 1 The prevalence of postpartum women with an EPDS score of $\geq 9$ in each month after delivery $(n=633)$. Participants who delivered between February 1, 2011 and October 31, 2011 The study questionnaires were returned from September 1, 2011 to November 30, 2011

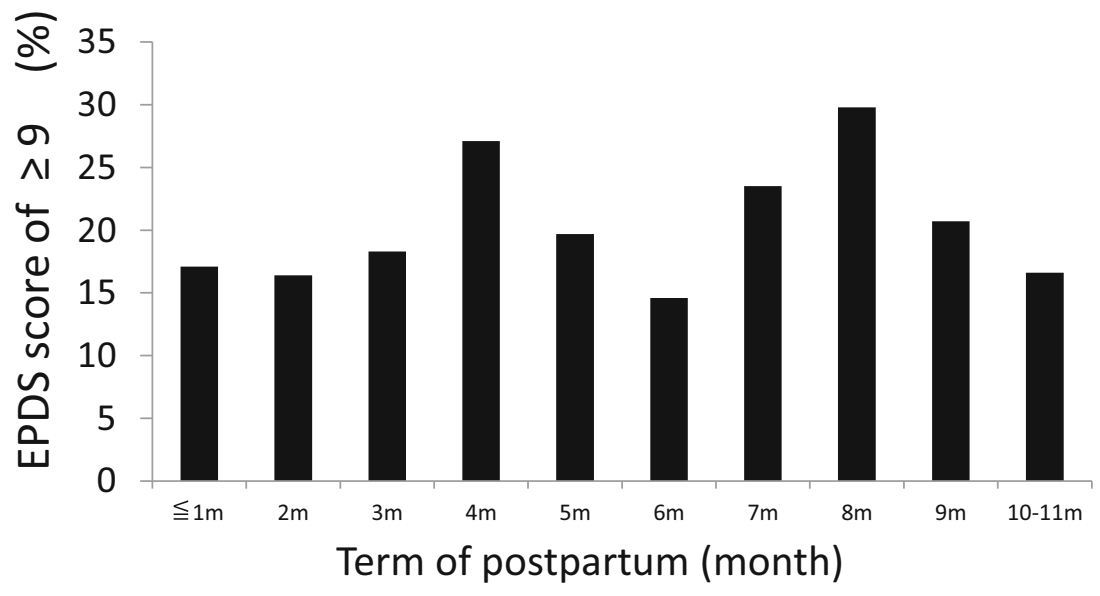

Data collection

We collected the data from the self-administered questionnaires. The cutoff score of EPDS among the Japanese population is 9 , which is considered to represent a significant risk factor for postpartum depression (Okano et al. 1996).

\section{Analysis}

Both the percentage of women with an EPDS score of $\geq 9$ and the univariate analysis of their backgrounds were analyzed. Student's $t$ test, the chi-square test, and Fisher's test were used where appropriate for statistical analysis.

Multivariate logistic regression analyses were performed after adjusting for variables significantly associated with an EPDS score of $\geq 9$ in a univariate analysis and the traditional risk factors for postpartum depression, including age, primiparous status, obstetric complications during pregnancy, employment, and death of loved ones. Adjusted odds ratios (ORs) and $95 \%$ confidence intervals (CIs) were calculated to estimate the risk of an EPDS score of $\geq 9$. All statistical analyses were performed using SAS ver. 9.3 statistical software (SAS Institute Inc., Cary, NC, USA).

\section{Results}

The questionnaires were returned from 677 participants, of which 633 were eligible for analysis. The prevalence of postpartum women with an EPDS score of $\geq 9$ was $21.3 \%$. Figure 1 shows the prevalence of postpartum women with an EPDS score of $\geq 9$ each month after delivery. Univariate analysis showed that age below 25 years $(P=0.0153)$, obstetric complications during pregnancy $(P=0.03)$, baby's birth weight under $2500 \mathrm{~g}(P=0.0117)$, destruction of the home ( $P=0.0335)$, and exposure to the tsunami $(P=0.0016)$ were significantly different between women with an EPDS score of $\geq 9$ and those with a score of $<9$. Multivariate analysis showed that age below 25 years (OR, 2.539; $95 \%$ CI, 1.155.60), baby's birth weight under $2500 \mathrm{~g}$ (OR, 2.28; $95 \% \mathrm{CI}$, 1.27-4.09), and exposure to the tsunami (OR, 1.80; $95 \% \mathrm{CI}$, $1.16-2.78)$ were significantly and independently associated with an EPDS score of $\geq 9$ (Table 1).

\section{Discussion}

In this study, the prevalence of postnatal women with an EPDS score of $\geq 9$ was $21.3 \%$. A previous large population study on Japanese women with postnatal depression reported that $13.9 \%$ of women had an EPDS score of $\geq 9$ (Suzumiya et al. 2004). Our results indicated that postnatal women in Miyagi prefecture's coastal area had a remarkably higher prevalence of EPDS score of $\geq 9$ after the disaster.

Table 1 Multivariate logistic regression analyses for postpartum women with an EPDS score of $\geq 9$

\begin{tabular}{lll}
\hline & $\begin{array}{l}\text { Odd } \\
\text { ratio }\end{array}$ & $\begin{array}{l}95 \% \text { confidence } \\
\text { interval }\end{array}$ \\
\hline Age & & \\
$\quad \geq 35$ years & 1.00 & \\
$30-34$ years & 1.213 & $0.725-2.031$ \\
$25-29$ years & 1.723 & $0.994-2.987$ \\
$\quad<25$ years & 2.539 & $1.151-5.599$ \\
Multipara (primipara $=0)$ & 1.371 & $0.848-2.217$ \\
No employment $($ employment $=0)$ & 1.464 & $0.978-2.192$ \\
Postpartum $6 \sim 11$ months $(\leq 5$ month $=0)$ & 1.161 & $0.776-1.736$ \\
Birth weight $\leq 2500 \mathrm{~g}(>2500 \mathrm{~g}=0)$ & 2.278 & $1.269-4.091$ \\
Temporary dwelling or refuge $($ own house $=0)$ & 1.486 & $0.686-3.217$ \\
Exposure to the tsunami $($ no exposure $=0)$ & 1.795 & $1.157-2.784$ \\
\hline
\end{tabular}

Adjusted by postpartum depression, including age, primiparous status, obstetric complications during pregnancy, employment, and death of loved ones 
As demonstrated in Fig. 1, the prevalence of a high-risk group for postpartum depression did not exhibit any correlations with the time interval after delivery. These results might suggest that postpartum women have been under chronically stressful conditions even 6 months after the disaster. Further investigations are needed to clarify the precise factors correlated to their situations.

With regard to the risk factors for perinatal depression related to the disaster, previous studies found that exposure to the storm (Xiong et al. 2010), loss of resources (Ehrlich et al. 2010), high earthquake exposure (Qu et al. 2012), and anxiety about earthquakes (Hibino et al. 2009) were more likely to cause depression in pregnant and postnatal women affected by natural disasters. In the present study, we found that exposure to the tsunami was a significant risk factor for postnatal depression. The tsunami disaster was totally unexpected for this vulnerable population; therefore, psychological trauma was much more severe than in previous natural disasters. Interventions of medical and mental care should be carried out immediately to prevent deterioration of maternal pathologic conditions and to observe newborns' development closely.

\section{Study limitations}

This study has some limitations. It was a cross-sectional study with possible self-report bias, so determining causal relationships was not possible. The prevalence of participants was low, so there was bias toward convenience sampling, and the results may not be applicable to all perinatal women in Miyagi prefecture's disaster-affected communities.

\section{Conclusions}

In conclusion, the prevalence of postnatal women with an Edinburgh Postnatal Depression Scale (EPDS) score of $\geq 9$ was $21.3 \%$ around 6 months after the disaster. Exposure to the tsunami was more likely to cause postnatal depression in postnatal women. Postnatal women and their children should be treated as a vulnerable population, and a further protective framework is necessary to establish preparedness for future devastating disasters.

Acknowledgments This work was supported by the Health Labour Sciences Research Grant Number H24.Jisedai-shitei 006(fukkou).

Open Access This article is distributed under the terms of the Creative Commons Attribution License which permits any use, distribution, and reproduction in any medium, provided the original author(s) and the source are credited.

\section{References}

Cox JL, Holden JM, Sagovsky R (1987) Detection of postnatal depression: development of the 10-item Edinburgh Postnatal Depression Scale. Br J Psychiatry 150:782-786

Ehrlich M, Harville E, Xiong X, Buekens P, Pridjian G, Elkind-Hirsch K (2010) Loss of resources and hurricane experience as predictors of postpartum depression among women in southern Louisiana. J Womens Health (Larchmt) 19(5):877-884. doi:10.1089/jwh.2009. 1693

Harville EW, Xiong X, Pridjian G, Elkind-Hirsch K, Buekens P (2009) Postpartum mental health after Hurricane Katrina: a cohort study. BMC Pregnancy Childbirth 9:21. doi:10.1186/1471-2393-9-21

Hibino Y, Takaki J, Kambayashi Y, Hitomi Y, Sakai A, Sekizuka N, Ogino K, Nakamura H (2009) Relationship between the NotoPeninsula earthquake and maternal postnatal depression and childrearing. Environ Health Prev Med 14(5):255-260. doi:10.1007/ s12199-009-0090-0

Okano T, Murata M, Msuji F, Tamaki R, Nomura J, Miyaoka H, Kitamura $\mathrm{T}$ (1996) Validation and reliability of Japanese version of the EPDS. Arch Psychiatr Diagn Clin Eval 7:525-533, Article in Japanese with English abstract

Qu Z, Wang X, Tian D, Zhao Y, Zhang Q, He H, Zhang X, Xu F, Guo S (2012) Post-traumatic stress disorder and depression among new mothers at 8 months later of the 2008 Sichuan earthquake in China. Arch Womens Ment Health 15(1):49-55. doi:10.1007/s00737-0110255-X

Suzumiya H, Yamashita H, Yoshida K (2004) Hoken Kikan ga Jishisuru Boshi houmon taisyosha no sango utsu byou zenkoku tashisetsu chosa (article in Japanese). Kousei no Shihyo 51:1-5

Xiong X, Harville EW, Mattison DR, Elkind-Hirsch K, Pridjian G, Buekens P (2010) Hurricane Katrina experience and the risk of post-traumatic stress disorder and depression among pregnant women. Am J Disaster Med 5(3):181-187 